\title{
The role of the clinical pharmacist in patient education and monitoring of patients under warfarin treatment
}

\author{
Fikret Vehbi İZzETTíN 1 * (D), Sevda ÇELİK 2 (D), Rezzan Deniz ACAR ${ }^{3}$ (D), Songül TEZCAN 2 (D), \\ Nilay AKSOY 4 (D), Muhammed Yunus BEKTAY 1 (D), Mesut SANCAR 2 (D)
}

1 Department of Clinical Pharmacy, Faculty of Pharmacy, Bezmialem Vakif University, Istanbul, Turkey.

2 Department of Clinical Pharmacy, Faculty of Pharmacy, Marmara University, Istanbul, Turkey.

3 Kartal Koşuyolu Training Research Hospital, Istanbul, Turkey.

4 Department of Clinical Pharmacy, Faculty of Pharmacy, Altinbas University, Istanbul, Turkey.

* Corresponding Author. E-mail: fvizzettin@hotmail.com (F.V.İ.); Tel. +90-212-523 2288.

Received: 20 June 2019 / Revised: 31 July 2019 / Accepted: 05 August 2019

\begin{abstract}
This study was carried out on patients who were under anticoagulation treatment with warfarin, at the outpatient cardiology clinic. The aim was to determine the effectiveness of pharmacist consultation, education, and intervention on each patient's therapeutic results. A cross-sectional randomized trial has been done. Twenty-five patients were included in the study. The Oral Anticoagulation Knowledge (OAK) Test, Short Form-36 (SF-36) and Duke Anticoagulation Satisfaction Scale (DASS) were applied. Patients resumed their routine anticoagulation treatment and INR and complications were recorded during the study. Additionally, patients received patient education, consultation on lifestyle and anticoagulant usage issues from a pharmacist. The same tests were applied again to the patients on the 90th day of the study and the results were compared with the initial test. Maintenance of INR within the target range and complication rates were compared before and after the intervention. Pre-test and post-test results of the patients revealed statistically significant improvements on the physical and mental score components of the SF-36 ( $p=0.001 ; \mathrm{p}$ $=0.001)$, OAK test scores $(\mathrm{p} \leq 0.001)$ and the (negative) "limitations" and "burdens" and "positive effects" components of the DASS $(p=0.005 ; p<0.001 ; p=0.001)$. The successful maintenance of INR within target range was significantly higher $(p=0.027)$. The positive effects of pharmacist consultation and education on therapeutic results were demonstrated.
\end{abstract}

KEYWORDS: Warfarin; anticoagulation; monitoring; clinical pharmacist.

\section{INTRODUCTION}

Warfarin is a vitamin K-dependent anticoagulant most frequently used to control and prevent thromboembolic events. Warfarin is still the most commonly prescribed anticoagulant worldwide. It is the only option for mechanical valve patients, but new oral anticoagulants have become available for patients with non-valvular atrial fibrillation (AF), pulmonary embolism, deep venous thrombosis, ischemic stroke, left ventricular mural thrombus after acute myocardial infarction, and left ventricular assist devices [1]. Currently, warfarin is still the most commonly used anticoagulant in the Turkish population and is mainly used in mechanical valve replacement (42.6\%) and non-valvular AF (38.4\%) [2].

Warfarin has a narrow therapeutic range and its use is associated with increased risk of gastrointestinal bleeding and hemorrhagic stroke [3]. Since warfarin has a wide interpatient variability, healthcare professionals face difficulties in patient treatment and follow-up. Studies have shown that uncontrolled INR values lead to serious complications [4]. Several factors have been shown to alter anticoagulant activity, including warfarin dose [5], drug and food interactions [6], patient sleep patterns [7], and patient education and understanding of the treatment [8].

In order to maintain the appropriate therapeutic range, appropriate management of anticoagulation therapy is required. In order to improve patient outcomes, this management should be systematic, standardized, coordinated and intensive [8]. Time in therapeutic range (TTR) is an estimate of the number of days that a patient has an INR value within their target range [9]. TTR, reduction of major bleeding events and enhanced patient satisfaction are the main therapeutic outcomes [9]. Monitoring of INR tests, convinient dose

How to cite this article: Izzettin FV, Celik S, Acar RD, Tezcan S, Aksoy N, Bektay MY, Sancar M. The role of the clinical pharmacist in patient education and monitoring of patients under warfarin treatment. J Res Pharm. 2019; 23(6): 1157-1163. 
adjustments, effective communication with the patient, proper treatment plan and continuous patient education form the gold standard of any anticoagulant management program [8].

Many alternative models have been developed for monitoring oral anticoagulant therapy. Anticoagulant monitoring by a specialist or directly by a family physician is one well-known method [12]. In Canada, the multidisciplinary family health team is another model used to expand the role of non-physician health care providers in direct patient care [9].

Recently, a pharmacist-led INR clinic model has been introduced in the USA, Canada, South Korea, Saudi Arabia and many other countries worldwide [9-13]. Many studies have addressed the efficacy of these clinics [14-18].

In a comparative study of pharmacist-and junior physician-managed anticoagulant therapies [19], parameters such as hospital stay, total cost, and an INR greater than 5 were used as comparison criteria. The results showed that the pharmacists significantly surpassed the junior physicians in achieving therapeutic INRs, with subsequent shorter hospital stays and lower costs. A variety of studies have demonstrated the role of the clinical pharmacist in anticoagulant management in both inpatient and outpatient settings.

In this study, the aim was to determine the effect of pharmacist involvement in the warfarin management process over a period of at least three months. This study evaluated the effects of the interventions of education, life-style guidance and warfarin usage counseling on the quality of life of the patients, their level of awareness about their treatment, and the therapeutic outcomes of their treatment.

\section{RESULTS}

\subsection{Demographic characteristics of patients}

The mean age of patients was $53.24 \pm 2.18$ of years and $56 \%$ of patients were female. The sociodemographic characteristics of the patients are presented in Table 1.

\subsection{Quality of life scores}

After three months of the study, the SF36PCS (Short Form 36 Physical Component Score) and SF36MCS (Short Form 36 Mental Component Score) were increased and results were statistically significant (Table 2).

\subsection{Awareness levels vis-à-vis treatment}

The number of correct answers in the OAK pre-test of patients was increased and results were statistically significant after three months of the study $(\mathrm{p}<0.001)$ (Table 3$)$.

\subsection{Satisfaction with treatment}

Total DASS scores, DASS "limitations" scores, DASS "burdens" scores and DASS "positive effects" scores were improved and were statistically significant $(p<0.05)$ (Table 4$)$. In case of 'positive effects' of DASS has inverse relation with scores which means decreasing number of scores indicates increased satisfaction.

\subsection{INR results and complications}

In the initial INR results, $52 \%$ of patients did not fall within the target INR range. At the end of the study, the INR results showed that $88 \%$ of patients were determined to be within the target INR range. The increase in the number of patients within the target INR range was statistically significant $(p=0.027)$. During the course of the study, $4 \%$ of patients had an emergency room visit due to bleeding.

\section{DISCUSSION}

According to a recently published article, the Turkish population has a low level of time in therapeutic range (TTR) and little patient awareness of warfarin. Of the many factors affecting the TTR level, some are modifiable (e.g., drug-drug interaction) and others are not (e.g., age and comorbidities) [2].

This study aimed to evaluate the role of the clinical pharmacist in improving the therapeutic effect, patient awareness and quality of life during the warfarin treatment process.

In this study, over a period of at least three months, clinical pharmacists were included in the warfarin management process of 25 patients enrolled in the study.

The level of the patients' awareness of their treatment, their level of satisfaction with the treatment and their general quality of life were assessed. Complications during treatment and achievement of target INR levels were continuously observed. 
Table 1. Sociodemographic characteristics of the patients.

\begin{tabular}{|c|c|c|}
\hline & & $\mathrm{n}=\mathbf{2 5}$ \\
\hline \multicolumn{3}{|l|}{ Sex } \\
\hline & Female & $56 \%$ \\
\hline & Male & $44 \%$ \\
\hline Age (mean \pm SE) & & $53.24 \pm 2.18$ \\
\hline \multicolumn{3}{|l|}{ Marital status } \\
\hline & Married & $88 \%$ \\
\hline & Single & $12 \%$ \\
\hline \multicolumn{3}{|l|}{ Educational status } \\
\hline & Lower & $64 \%$ \\
\hline & Higher & $36 \%$ \\
\hline \multicolumn{3}{|l|}{ Work status } \\
\hline & Unemployed & $56 \%$ \\
\hline & Employed & $44 \%$ \\
\hline \multicolumn{3}{|l|}{ Smoking status } \\
\hline & Smoker & $4 \%$ \\
\hline & Non-smoker & $96 \%$ \\
\hline \multicolumn{3}{|l|}{ Alcohol use } \\
\hline & No & $100 \%$ \\
\hline & Yes & 0 \\
\hline \multicolumn{3}{|c|}{ Herbal product use } \\
\hline & No & $76 \%$ \\
\hline & Yes & $24 \%$ \\
\hline \multicolumn{3}{|c|}{ Other chronic diseases } \\
\hline & No & $80 \%$ \\
\hline & Yes & $20 \%$ \\
\hline \multicolumn{3}{|c|}{ Warfarin indications } \\
\hline & AF & $20 \%$ \\
\hline & DVT & - \\
\hline & PE & - \\
\hline & VR & $56 \%$ \\
\hline & VE & $8 \%$ \\
\hline & AF+VR & $8 \%$ \\
\hline & DVT+PE & $4 \%$ \\
\hline & $\mathrm{AF}+\mathrm{DVT}$ & $4 \%$ \\
\hline \multicolumn{3}{|c|}{ ATC distribution of drug used } \\
\hline & vascular drugs & $46 \%$ \\
\hline & a medications & $56 \%$ \\
\hline & system drugs & $52 \%$ \\
\hline & system drugs & $16 \%$ \\
\hline & system drugs & - \\
\hline
\end{tabular}

\subsection{Patient knowledge}

In this study, there was a significant increase in the scores of the oral anticoagulant knowledge test after three months of the study. This result highlights the immense role played by counseling and education in expanding patient knowledge and awareness and hence, the subsequent improvement in healthcare outcomes. This finding concurred with results of previous studies done in different countries and showed that patient understanding of oral anticoagulants had been improved via the pharmacist intervention, even in patients with a low level of literacy, and that patients consequently had achieved better outcomes [22, 23].

Many studies have demonstrated the benefits of educating patients about their anticoagulant therapy $[22,23]$. In a study conducted by Tang et al, there was a positive correlation between patient knowledge acquired from counseling programs and achievement of the target INR range [24]. Other study has shown that, three months after discharge, patients who had participated in education programs had reduced their risk of hemorrhagic events or thrombotic recurrence [25]. 
Table 2. Pre- and post-scores for quality of life in patients (SF36).

\begin{tabular}{cccc}
\hline & Pre- score & Post- score & $\mathbf{P}^{*}$ \\
\hline SF36 PCS & $40.36 \pm 2.54$ & $42.25 \pm 2.33$ & $p=0.001$ \\
SF36 MCS & $46.54 \pm 1.91$ & $48.45 \pm 1.73$ & $p=0.001$ \\
\hline SF36 PCS: Short Form 36 Physical Component Score; SF36MCS: Short Form 36 Mental Component Score &
\end{tabular}

Table 3. Pre- and post-scores for OAK test in patients.

\begin{tabular}{rcc}
\hline & OAK test score & $P^{*}$ \\
\hline Pre- score & $8.16 \pm 3.55$ & $p<0.001$ \\
Post- score & $15.16 \pm 3.46$ & \\
\hline OAK: oral anticoagulation knowledge &
\end{tabular}

Table 4. Pre- and post-scores for DASS in patients.

\begin{tabular}{lccc}
\hline & Pre- score & Post- score & $\mathbf{P}^{*}$ \\
\hline Total score & $65.12 \pm 2.94$ & $53.96 \pm 2.29$ & $P=0.005$ \\
Limitations score & $18.48 \pm 1.28$ & $17.6 \pm 1.18$ & $p=0.005$ \\
Burdens score & $14.72 \pm 1.10$ & $12.28 \pm 0.83$ & $p \leq 0.001$ \\
Positive effects score & $31.72 \pm 1.29$ & $25.4 \pm 1.76$ & $p=0.001$ \\
\hline DASS: Duke Anticoagulation Satisfaction Scale & &
\end{tabular}

\subsection{Quality of life}

When the quality of life of the patients was examined by the SF-36 test, the physical and mental component scores of the patients were significantly improved. Many studies have been conducted to assess the role of clinical pharmacist intervention in improving the quality of life of diabetic, hypertensive, asthmatic, heart failure, tuberculosis and warfarin- and multi drug-using patients [26, 27]. All these studies demonstrated that clinical pharmacist interventions had a positive impact on patient quality of life.

\subsection{Patient satisfaction}

The mean scores of the DASS scale were decreased from $65.12 \pm 2.94$ to $53.96 \pm 2.29$ after three months of the study. When "limitations", "burdens" and "positive effects" on the patients under oral anticoagulant therapy were reviewed before and after three months of the study, the DASS "limitations" preliminary score was $18.48 \pm 1.28$, while the final score was reduced to $17.46 \pm 1.18$. Patients well-informed about drug and food interactions were more comfortable in their choices, thus reducing their fear and restrictions in selecting drugs and food. The DASS "burdens" preliminary score was $14.72 \pm 1.10$, while the final score fell to $12.28 \pm 0.83$. The daily burdens on patients requiring attention (e.g., dietary needs, medication dose, times and interactions) and the monthly burdens (e.g., going to the hospital for INR follow-up) decreased as their awareness levels and education concerning their treatment process and medication increased. The DASS "positive effects" prescore was $31.72 \pm 1.29$, whereas the final score had decreased to $25.4 \pm 1.76$. Thus, the greatest improvement was in the DASS "positive effects" post-test. Patients who understood the causes and requirements of their treatment were more satisfied with the treatment and their confidence in their treatment increased. The results of the total DASS scores were comparable to those of other studies. The mean DASS scores were 54.58 in two other studies and 45 in another [17]. Lower scores represent higher satisfaction with oral anticoagulant therapy, fewer limitations, less stress, and less psychological impact for the patients.

\subsection{Target INR range}

In the initial INR results, $52 \%$ of patients did not fall within the target INR range. At the end of the study, the INR results showed that $88 \%$ of patients had achieved an INR score within the target range. In the final measurements, patients had improved by $40 \%$, indicating that the pharmacist's intervention and counseling had a positive effect on reaching the target INR range. In studies of physician- and pharmacist- 
conducted anticoagulant treatment management, the pharmacists were shown to achieve better control of the INR than the physicians [14, 28].

\subsection{Emergency room visits}

Throughout the duration of the study, $4 \%$ of patients required emergency services due to GIS bleeding after receiving nonsteroidal anti-inflammatory drugs (NSAIDs) medication. The fact that there were fewer complications in the patients showed the importance of the patient education and counseling service in treatment success and prevention of complications. This result supports the findings that a low level of information about warfarin increases the incidence of adverse reactions [29]. In their study, Khudair et al. reported that in hospitals where pharmacists were not included in warfarin therapy, $6.2 \%$ higher mortality rate, $5.86 \%$ longer hospitalization, $2.16 \%$ higher medical costs and $8.9 \%$ more bleeding were observed, compared to hospitals that included pharmacist management in the therapy [30]. These results were confirmed by the present study.

In parallel with the presented results, other studies have also shown that a systematic and coordinated anticoagulant monitoring service with a pharmacist, participants performed better compared to standard anticoagulation management treatment [25].

\section{CONCLUSION}

In conclusion, through counseling and education, pharmacist interventions in the warfarin management process were found to produce positive results in the quality of life, treatment satisfaction and level of awareness of the patients concerning their treatment, as well as better therapeutic outcomes and reduced risk of complications.

Because of time limitation the number of patients were limited.

\section{MATERIALS AND METHODS}

The study was approved by the local ethics committee and carried out in the cardiology clinic. This study was a cross sectional randomized study and included 25 patients who were diagnosed with venous thromboembolism or prosthetic valve replacement and who were scheduled for anticoagulation treatment for at least three months. Data including sociodemographic characteristics (age, sex, educational status, existing diseases, and use of drugs, herbal supplements, alcohol and tobacco) along with the prescribed Coumadin ${ }^{\circledR} /$ warfarin dose and the target INR value were recorded for each patient at the initial visit.

The patients received routine treatment and value of INR and complications were recorded upon the admission to study. Additionally, the level of knowledge about the drug used by the patient and the quality of life were measured by administering the OAK [20], the SF-36 [21] and the DASS tests (http://tgkdc.dergisi.org/summary.php3?id=2106) were applied within the first day of admission. Also training and counseling on lifestyle and medication use were provided to the patients. When the dose had been changed by the physician, a second interview was conducted 8-10 days after the first visit. The 2nd, 3rd and 4th interviews of patients who had not undergone a dose change were conducted at 4-week intervals. In interviews conducted with patients, INR was measured, and they were evaluated on issues which included monitoring warfarin use and related educational support, finding solutions for any problems, checking for interaction with other drugs used by the patient, monitoring adverse/side effects and checking whether the target INR value had been achieved, whether the effects of anticoagulation therapy had been observed, and whether or not any unplanned physician visits had taken place.

On the 90th day, the tests administered to the patients on the first visit were repeated and the pre- and post-test results were compared. Additionally we compared in terms of their success in keeping within the target INR range and frequency of complication development, and the effectiveness of the pharmacist's education and counseling support was examined.

\subsection{Statistical evaluation}

The continuous variables were mean \pm standard deviation and ordinal and nominal values were calculated as $\mathrm{n}(\%)$. The measurable variables were compared using the Student's t-test for conditions with normal distribution, and the non-parametric form of the same test, the Mann Whitney $U$ test, was applied for non-normal distribution. The Chi-square test was used to compare categorical data. The paired sample t-test was used to compare the pre- and post-treatment data. The SPSS (Statistical Package for Social Sciences) for 
Windows 16.0 program was used in the analyses. The results were evaluated at a $95 \%$ confidence interval and at a significance level of $\mathrm{p}<0.05$.

Acknowledgements: The authors of this study are thankful to doctors and staffs of cardiology clinics of Kartal Koşuyolu Training Research Hospital. This study has not been funded by any organization. There are no conflict of interest between authors of this article.

Author contributions: Concept - F.V.I., S.C., R.D.A., M.S.; Design - F.V.I., S.C., R.D.A., S.T., M.S.; Supervision - F.V.I., R.D.A., S.T., M.S.; Materials - F.V.I., S.C. R.D.A., N.A., S.T.; Data Collection and/or Processing - S.C., R.D.A., S.T., M.Y.B.; Analysis and/or Interpretation -F.V.I., N.A., S.T., M.S.; Literature Search - S.C., N.A., S.T., M.Y.B.; Writing F.V.I., S.C., S.T., M.Y.B.; Critical Reviews - F.V.I., S.C., R.D.A., S.T., N.A., M.Y.B., M.S.

Conflict of interest statement: The authors declared no conflict of interest

\section{REFERENCES}

[1] Kernan WN, Ovbiagele B, Black HR, Bravata DM, Chimowitz MI et al. Guidelines for the prevention of stroke in patients with stroke and transient ischemic attack: a guideline for healthcare professionals from the American Heart Association/American Stroke Association. Stroke. 2014; 45: 2160-2236. [CrossRef]

[2] Çelik A, İzci S, Kobat MA, Ateş AH, Çakmak A et al. The awareness, efficacy, safety, and time in therapeutic range of warfarin in the Turkish population: WARFARIN-TR. Anatol J Cardiol. 2016; 16: 595-599. [CrossRef]

[3] Chen W, Chen Y, Hsu P, Tsay F, Chan H et al. Gastrointestinal hemorrhage in warfarin anticoagulated patients: incidence, risk factor, management, and outcome. BioMed Res Int. 2014; 29: 1-7. [CrossRef]

[4] Holbrook A, Schulman S, Witt DM, Vandvik PO, Fish J et al. Evidence-based management of anticoagulant therapy: Antithrombotic Therapy and Prevention of Thrombosis, 9th ed: American College of Chest Physicians EvidenceBased Clinical Practice Guidelines. Chest. 2012; 141(2 Suppl): 152-184. [CrossRef]

[5] Hope KA, Havrda DE. Subtherapeutic INR values associated with a switch to generic warfarin. Ann Pharmacother. 2001; 35: 183-187. [CrossRef]

[6] Wittkowsky AK. Dietary supplements, herbs and oral anticoagulants: the nature of the evidence. J Thromb Thrombolysis. 2008; 25: 72-77. [CrossRef]

[7] Davis NJ, Billett HH, Cohen HW, Arnsten JH. Impact of adherence, knowledge, and quality of life on anticoagulation control. Ann Pharmacother. 2005; 39: 632-636. [CrossRef]

[8] Krittathanmakul S, Silapachote P, Pongwecharak J, U Wongsatit. Effects of pharmacist counseling on outpatients receiving warfarin at Songklanagarind Hospital. Songkla Med J. 2006; 24: 93-99.

[9] Rossiter J, Soor G, Telner D, Aliarzadeh B, Lake J. et al. A pharmacist-led point-of-care INR clinic: optimizing care in a family health team setting. Int J Family Med. 2013; 2013: 1-4. [CrossRef]

[10] Reinders TP, Steinke WE. Pharmacist management of anticoagulant therapy in ambulant patients. Am J Health-Syst Pharm. 1979; 36: 645-648.

[11] Choe HM, Kim J, Choi KE, Mueller BA. Implementation of the first pharmacist-managed ambulatory care anticoagulation clinic in South Korea. Am J Health-Syst Pharm 2002; 59: 872-874. [CrossRef]

[12] Dib J, Mohammed K, Momattin H, Alshehri AM. Implementation of pharmacist-managed anticoagulation clinic in a saudi arabian health center. Hospital Pharmacy. 2014; 49: 260-268. [CrossRef]

[13] Manji I, Pastakia SD, Do AN, Ouma MN, Schellhase E, et al. Performance outcomes of a pharmacist-managed anticoagulation clinic in the rural, resource-constrained setting of Eldoret, Kenya. J Thromb Haemost. 2011; 9: 22152220. [CrossRef]

[14] Carvalho AR, Ciol MA, Tiu F, Rossi LA, Dantas RAS et al. Oral Anticoagulation: the impact of the therapy in healthrelated quality of life at six-month follow-up. RLAE. 2013; 21: 105-112. [CrossRef]

[15] Lakshmi R, James E, Kirthivasan R. Study on impact of clinical pharmacist's interventions in the optimal use of oral anticoagulants in stroke patients. Indian J Pharm Sci. 2013;75: 53-59. [CrossRef]

[16] Collins S, Barber A, Sahm LJ. Pharmacist's counselling improves patient knowledge regarding warfarin, irrespective of health literacy level. Pharmacy. 2014; 2: 114-123. [CrossRef]

[17] Stafford L, Tienen EC, Bereznicki LR, Peterson GM. The benefits of pharmacist delivered warfarin education in the home. IJPP. 2012; 20: 384-389. [CrossRef] 
[18] Winans AR, Rudd KM, Triller D. Assessing anticoagulation knowledge in patients new to warfarin therapy. Ann Pharmacother. 2010; 44: 1152-1157. [CrossRef]

[19] Hosmane SR, Tucker J, Osman D, Williams S, Waterworth P. et al. Inpatient oral anticoagulation management by clinical pharmacists: safety and cost effectiveness. J Clin Med Res. 2010; 2: 90-92. [CrossRef]

[20] Zeolla MM, Brodeur MR, Dominelli A, Haines ST, Allie ND. Et al. Development and validation of an instrument to determine patient knowledge: the oral anticoagulation knowledge test. Ann Pharmacother. 2006; 40: 633-638. [CrossRef]

[21] Kocyigit H, Aydemir O, Fisek G, Ölmez N, Memiş AK. Et al. Kisa Form 36'nin Türkce Versiyonunun Güvenilirligi ve Gecerliligi. Ilac ve Tedavi Dergisi. 1999; 12: 102- 106.

[22] Beyth R, Quinn L, Landefeld C. A multicomponent intervention to prevent major bleeding complications in older patients receiving warfarin: A randomized, controlled trial. Ann Int Med. 2000; 133: 687-1395. [CrossRef]

[23] Khan TI, Kamali F, Kesteven P, Avery P, Wynne H. et al. The value of education and self monitoring in the management of warfarin therapy in older patients with unstable control of anticoagulation. Br J Haematol. 2004; 126: 557-564. [CrossRef]

[24] Tang EO, Lai CS, Lee KK, Wong RS, Cheng G. et al. Relationship between patients' warfarin knowledge and anticoagulation control. Ann Pharmacother. 2003; 37: 34-39. [CrossRef]

[25] Walraven C, Jennings A, Oake N, Fergusson D, Forster AJ. Et al. Effect of study setting on anticoagulation control: a systematic review and metaregression. Chest. 2006; 129: 1155-1166. [CrossRef]

[26] Ramanath KV, Balaji DB, Nagakishore CH, Kumar SM, Bhanuprakash M. et al. A study on impact of clinical pharmacist interventions on medication adherence and quality of life in rural hypertensive patients. J Young Pharm. 2012; 4: 95-100. [CrossRef]

[27] Jennings DL, Ragucci KR, Chumney EC, Wessell AM. Impact of clinical pharmacist intervention on diabetes related quality-of-life in an ambulatory care clinic. Pharm Pract (Granada). 2007; 5: 169-173.

[28] Boddy C. Pharmacist involvement with warfarin dosing for inpatients. Pharm World. 2001; 23: 31-35.

[29] Roche-Nagle G, Chambers F, Nanra J, Bouchier-Hayes D, Young S. et al. Evaluation of patient knowledge regarding oral anticoagulants. Irish Medical Journal. 2003; 96: 211-213.

[30] Khudair IF, Hanssens YI. Evaluation of patients' knowledge on warfarin in outpatient anticoagulation clinics in a teaching hospital in Qatar. Saudi Med J. 2010; 31: 672-677.

This is an open access article which is publicly available on our journal's website under Institutional Repository at http://dspace.marmara.edu.tr. 